\title{
Eventos comunicativos interculturales: la reflexividad sociolingüística en el discurso público sobre las diferencias ${ }^{1}$
}

\section{Intercultural communicative events: sociolinguistic reflexivity in public discourse about differences}

\author{
Emma Hilda Ortega Rodríguez ${ }^{2}$ \\ Universidad de Ciencias y Artes de Chiapas (UNICACH) \\ (iD) https://orcid.org/0000-0003-4351-8339
}

Resumen: El presente artículo muestra el tratamiento discursivo que el gobierno mexicano ha conferido al tema de la diversidad cultural y lingüística del país a través de un dispositivo comunicativo propuesto aquí como evento comunicativo intercultural: un arreglo pragmático que cobró auge particularmente en la Ciudad de México durante 2010 y 2012, en el marco del Bicentenario de la independencia y revolución mexicanas, y caracterizado por mantener como eje temático la reivindicación política de las múltiples identidades nacionales a través de formulaciones argumentativas tendientes a una posible coyuntura política. La investigación se sustenta en un enfoque metodológico que vincula dos propuestas teóricas: la etnografía del habla, una perspectiva antropológica casi olvidada para delinear el contexto de una interacción comunicativa; y la reflexividad sociolingüística, paradigma reciente de base filosófica y sociológica, el cual permite concebir al discurso metalingüístico como mecanismo regulativo de permanencia y adscripción cultural. De este modo, los resultados obtenidos enlazan dos niveles de análisis: 1) el arreglo pragmático en donde emerge la naturaleza intercultural de sus participantes, funciones e intenciones discursivas; y 2) los contenidos temáticos emanados de dichas interacciones. Ambos productos, en conjunto, muestran un fenómeno poco señalado por los estudiosos de la interculturalidad, y es que diacrónica y sincrónicamente el discurso público sobre las diferencias no ha mantenido un ánimo unificador hacia la ciudadanía mexicana; por el contrario, ha mostrado compromisos sin cumplir, acuerdos sin ratificar y demandas sin un adecuado seguimiento a manos de quienes participan, a todo nivel jerárquico, de estos encuentros. La conclusión general de ello es que los llamados eventos comunicativos interculturales funcionan como un mecanismo simbólico de contención ante posibles conflictos sociales de ímpetu cultural y con efectos políticos a largo plazo.

Palabras clave: etnografía del habla; reflexividad sociolingüística; interculturalidad

Recibido: 20/06/2018 | Aceptado: 12/07/2019 | Disponible en línea: 15/12/2019

Cómo citar este artículo: Ortega, E. (2020). Eventos comunicativos interculturales: la reflexividad sociolingüística en el discurso público sobre las diferencias. Jangwa Pana 19(1), 129 - 149. DOI: https://doi.org/10.21676/16574923.3358

\footnotetext{
1 Manifiesto no tener conflicto de intereses con respecto a las instituciones financiadoras y de apoyo para esta investigación; la redacción del manuscrito concierne al ejercicio investigativo, por lo cual soy independiente y responsable de la opinión que en él expreso.

${ }^{2}$ Correo electrónico: emmy_ortega@ @otmail.com.
} 
Abstract: This paper evinces the discursive treatment that Mexican government has given to cultural and linguistic diversity topic of its country through a communicative device proposed here as an intercultural communicative event: a pragmatic arrangement that particularly boomed in Mexico City during 2010 and 2012 , within the framework of the Bicentennial of the Mexican independence and revolution, and characterized by maintaining as thematic axis the political vindication of the multiple national identities through argumentative formulations about a possible political conjuncture. The research is based on a methodological approach that links two theoretical proposals: the ethnography of speech, an almost forgotten anthropological perspective to outline the context of a communicative interaction, and the sociolinguistic reflexivity, a recent paradigm with philosophical and sociological basis, which allows us to conceive metalinguistic discourse as a regulative mechanism of permanence and cultural ascription. Thereby, obtained results link two analysis levels: 1) The pragmatic arrangement where emerge the intercultural nature, functions and discursive intentions of participants; and 2) The thematic contents emanating from these interactions. Both products, on the whole, show a phenomenon little noted by the interculturalism researchers. It is that, diachronically and synchronously, public discourse about differences has not maintained a unifying spirit towards Mexican citizenship. On the contrary, it has shown unfulfilled commitments, agreements without ratification and demands without adequate continuity by all hierarchical levels participants in these meetings. General conclusion of this is that the named intercultural communicative events function as a symbolic mechanism for containning possible social conflicts of cultural origin and with long-term political effects.

Keywords: Ethnography of speaking; sociolinguistic reflexivity; interculturality

\section{Introducción}

Las interacciones sociales en escenarios multiculturales y plurilingües obligan a sus actores a mantener un intercambio continuo de saberes. Esta capacidad para reconocer al otro, además de funcionar como herramienta comunicativa, ha delineado su camino como lógica de planeación institucional, crisol de identidades y códigos culturales, los cuales no necesariamente se adhieren o toman rumbo hacia el indigenismo, como ha ocurrido en México desde épocas posrevolucionarias.

Actualmente, en cambio, existe un interés creciente por asumir la interculturalidad en un sentido amplio y como fundamento ético-político que responda a cambios sociales emergentes; como un diálogo que resuelva los conflictos ideológicos traídos consigo por la globalización y que represente el derecho a la democracia plural, en tanto garante de desarrollo en un entorno de conocimiento y respeto mutuo.

Para lograrlo, es menester el tránsito de la ciudadanía por un proceso gradual de sensibilización en donde las actitudes colectivas características de un Estado etnocéntrico, como la negación, la defensa y la minimización de lo diverso, cedan lugar a aquellas cualidades que se exigen cada vez más por los Estados cosmopolitas o etnorelativos, a saber: la aceptación, la adaptación y la posible integración de lo diverso en una sociedad pluralista (Bennett, 1993). Asimismo, se requiere la disposición de los agentes culturales al diálogo y, más importante aún, su reflexión en torno a los códigos de identificación usados al interior de las instituciones que conforman su quehacer cotidiano, es decir, hacia los sistemas lingüísticos empleados para ejercer la comunicación intercultural.

En este ánimo, el gobierno mexicano ha priorizado el ámbito educativo para dialogar sobre la complejidad idiomática del país, implementando el enfoque de la interculturalidad en los niveles básico, medio superior y superior en relación con un sector cuantitativamente menor, aunque cualitativamente relevante: el indígena u originario. Su documento más reciente y propositivo, el Programa especial de educación intercultural 2014-2018, se proyectó como 
un principio pedagógico y transversal que se consolidaría como la herramienta para promover la igualdad, la permanencia y la relevancia curricular entre las distintas culturas y lenguas de México (SEP-CGEIB, 2014); sin embargo, los resultados no tuvieron el alcance esperado.

Según el Instituto Nacional para la Evaluación de la Educación (INEE), la Educación Intercultural y Bilingüe (EIB) muestra dos grandes tendencias en nuestro país:

1. Las acciones de los gobiernos panistas entre 2000 y 2012, que plantearon la EIB para la ciudadanía en general al crear la Coordinación General de Educación Intercultural y Bilingüe (CGEIB), las universidades interculturales y el Instituto Nacional de Lenguas Indígenas (INALI), que mermaron durante el sexenio calderonista al reducir el alcance poblacional de dichos organismos.

2. El reciente impulso de la sociedad civil para diseñar y gestionar políticas educativas desde abajo (Sartorello, 2019).

En el mismo diagnóstico se señala que, desde el año 2000, dichas tendencias se han distanciado cada vez más, pues el concepto de interculturalidad se ha reemplazado por el de inclusión educativa al procurar la integración de aquellos grupos excluidos del referente sociocultural dominante. En consecuencia, se ha fomentado una perspectiva de déficit social, lingüístico y educativo incompatible con un enfoque intercultural en donde el reconocimiento constitucional de México, como nación diversa, entraña una orientación de enseñanzaaprendizaje pluricultural y de cobertura universal.

Sumado a lo anterior, si se considera que la interculturalidad convergente establece una dimensión relacional, dinámica e histórica entre sociedad nacional y pueblos indígenas, los recientes planteamientos del Instituto Nacional de los Pueblos Indígenas (INPI) apuntan hacia lo opuesto: una contracción funcional de las instituciones educativas, pues se postula una educación "indígena, intercultural y plurilingüe para revitalizar, desarrollar y fortalecer los elementos culturales y lingüísticos de los pueblos indígenas de México, para su mantenimiento y preservación" (INPI, 2019), es decir, lo intercultural nuevamente se procura para un sector muy específico de la población.

Este vaivén conceptual se ha valido de un aparato discursivo de difusión, cuyo arreglo pragmático involucra actores y temáticas que confluyen en espacios cerrados de discusión destinados a la reflexión y el seguimiento de la agenda intercultural. A modo de hipótesis, en este trabajo se propone que tal dispositivo - encargado, por lo general, de mantener una tendencia indigenista - se proyecta públicamente como un Evento Comunicativo Intercultural (ECI), cuya finalidad es ofrecer un espacio de diálogo y reivindicación hacia las identidades culturales que pueden ser, o no, de adscripción originaria o amerindia.

Por todo lo anterior, el objetivo general de esta investigación consiste en mostrar cómo a través del tratamiento discursivo que los participantes de los ECI confieren al tema de la diversidad cultural y lingüística de México se pretende contener posibles conflictos políticos entre dos universos simbólicos en tensión: la histórica comunidad de usuarios de lenguas nacionales frente a la reciente comunidad hispanoparlante. 
En este tenor, el corpus de eventos registrados emana de una lógica de observación inspirada en el clásico modelo de la etnografía del habla de Hymes (1972a), con especial énfasis en las unidades más ligadas a la comunidad de habla: el escenario que le enmarca, los participantes que le constituyen y el género que se le asigna en tanto hábito comunicativo relevante para el grupo social en cuestión. De este modo, se eligieron seis situaciones de habla, en el formato de coloquio, acontecidas durante los dos últimos años del primer auge del modelo intercultural (2010-2012), pues los planteamientos de esta etapa han resultado ejemplares para las políticas educativas recientes.

Para la clasificación del contenido discursivo de los ECI, se requirió un concepto analítico que colocara el tema de la lengua como principal indicador identitario, pues la afluencia de ciudadanos bilingües provenientes de toda la república mexicana fue consistente en cada encuentro; por ello, la propuesta de la reflexividad sociolingüística de Muñoz (2008) resultó pertinente en tanto discurso metalingüístico mediante el cual un sujeto del discurso se vale de su sistema lingüístico para hablar sobre el mismo.

Así, el alcance de esta propuesta puede entenderse como un esmero microetnográfico por comprender, a partir de interacciones específicas, los dispositivos de comunicación social sobre la gestión de la diversidad, pues aunque la pretensión del trabajo de campo fue cubrir los ECI con mayor poder de convocatoria hacia los ámbitos académico y político del interculturalismo en México, no todos los encuentros ofrecían situaciones de habla abiertas a la reflexión o con protocolos comunicativos flexibles para incorporar las opiniones vivenciales de sus participantes. Por ese hecho, la clasificación de los ECI podría mostrar limitaciones en cuanto a su poder predictivo sobre la actual agenda intercultural a nivel macroetnográfico, ya que aún queda por revisar el reciente despliegue de actividades conducentes al rediseño y aplicación de esta.

\section{Materiales y métodos}

\section{Área de estudio}

Esta investigación es de corte interdisciplinario y, metodológicamente, transita entre los lindes de la antropología lingüística, por su enfoque etnográfico, y la sociolingüística, por procurar el acceso al comportamiento linguístico de los hablantes desde un posicionamiento hermenéutico.

\section{El ajuste teórico-metodológico entre etnografía comunicativa y reflexividad sociolingüística}

A fin de sistematizar las observaciones sobre la estructura de los ECI, se optó por una metodología de corte cualitativo que permitiera sentar las dimensiones operativas del discurso, así como los significados derivados de estos. Por ello, se eligió una aproximación interdisciplinaria al estudio del lenguaje en su contexto sociocultural: la etnografía del habla, propuesta por Hymes (1964b: 13), para tomar como punto de partida el análisis de los hábitos comunicativos de una comunidad y determinar cuáles son sus formatos y respectivos componentes. 
Desde este enfoque, el punto analítico de partida fue el evento comunicativo (Hymes, 1964b) que, según Duranti (2000), paulatinamente se ha decantado a favor de un evento de habla, el cual, en sentido estricto, define a "aquellas actividades o aspectos de actividades gobernadas directamente por reglas o normas para el uso del habla" (Hymes, 1972a: 56). Actualmente, los eventos de habla son unidades de participación social que vinculan comunidades a través del uso del lenguaje y se definen en función de un contexto y de sus límites tanto a nivel lingüístico-cultural como físico. Dichos límites son asequibles, de principio a fin, en eventos formales, mientras que en los informales se delimitan con mayor dificultad.

Así, los eventos de habla componen, a su vez, unidades mayores de comunicación: las situaciones de habla, que son instancias asociadas a la presencia o ausencia de lenguaje en tanto se regulan por actividades en las que la acción de hablar no constituye el eje central para los participantes del escenario, pues la ausencia de habla "podría ser tan importante como su presencia en esas otras situaciones que hemos definido como eventos de habla" (Duranti, 2000: 386).

Ahora bien, en la investigación lingüística, la etnografía del habla apenas se ha valido del modelo SPEAKING de Hymes en su versión extensa ${ }^{3}$, pues el interés central ha sido la relación entre tres componentes de los eventos de habla, a saber:

- S (Setting: escenario, tiempo y lugar, o Scene: escenario psicológico)

- P (Participants: participantes, hablante, oyente, audiencia) y

- G (Genre: géneros en relación con determinadas esferas sociales, más allá de las propuestas escritas o literarias).

Aunque los citados elementos no son menores en importancia, el énfasis en considerar unidades más ligadas a la comunidad de habla como su escenario, sus participantes y el género en tanto hábito comunicativo relevante, deja ver un creciente interés hacia el tejido organizacional de los grupos culturales, una visión que va más allá de la forma o la estructura de los mensajes emitidos, así como por las normas e intenciones que rigen a los mismos. Este entramado entre contexto, actores y simbolización de prácticas comunicativas es el germen del motor social que Hymes propuso atender de la mano con postulados antropológicos. Aquí se propone una visión del lenguaje en tanto "conjunto de estrategias simbólicas que forman parte del tejido social y de la representación individual de mundos posibles o reales” (Duranti, 2000: 22).

Por todo lo anterior, en esta investigación se proyecta un concepto operativo inspirado en la propuesta original de evento comunicativo de Hymes (1964b), pues en ella el foco aún es el acto de habla y sus funciones discursivas; es decir, se enfatiza la dimensión pragmática de la

\footnotetext{
${ }^{3}$ Desde la etnografía del habla, el interés investigativo ha sido menor en relación con los otros componentes: -E (Ends: fines, propósitos como resultados y como metas)

-A (Act sequence: forma y contenido del mensaje)

-K (Key: clave o tono, manera o espíritu en que se ejecuta el acto de habla; canal oral o escrito, telegráfico, etc.) -I (Instrumentalities: formas de habla, lenguas o dialectos, códigos, variedades y registros) y

-N (Norms: normas de interacción e interpretación)
} 
lengua, pues la comprensión de la forma y del contenido del discurso implica la comprensión paralela de la actividad social en la que un acto de habla tiene lugar.

En ese sentido, un Evento Comunicativo Intercultural (ECI) se entiende como un arreglo de acciones discursivas de formato público, cuya intencionalidad recoge visiones de mundo diferentes pero que, en la acción comunicativa, argumenta a favor de la diversidad cultural como principal tarea de reconocimiento y validación de la historicidad. En un ECI se hallan distintos roles sociales puestos en acción, pero la organización jerárquica de los mismos depende del objetivo de la situación comunicativa y del establecimiento de significados compartidos al final de este.

Este viraje hacia el escenario, los participantes y el género de los eventos de habla toma un sentido hermenéutico que obliga a rescatar la dimensión intersubjetiva de los sujetos involucrados. Para el caso de los ECI, el contenido de los actos de habla perfila un espacio simbólico con dos universos en tensión, cuyos referentes identitarios proyectan a las lenguas nacionales u originarias como principal eje temático. Por consiguiente, aquí la etnografía comunicativa se asume como un esfuerzo por describir e interpretar una realidad discursiva "que se expresa a través de representaciones cognitivas, razonamientos, normatividades, evaluaciones y descripciones de los recursos lingüísticos y socioculturales de los hablantes" (Muñoz, 2008, p. 11); es decir, a través de una actividad de razonamiento metalingüístico denominada reflexividad sociolingüística: una herramienta de análisis discursivo.

\section{Corpus de trabajo y criterios de observación}

Se eligieron seis situaciones de habla, en el formato de coloquio. La orientación ideológica de ellas sitúa el tema de la interculturalidad como estrategia de reivindicación para las identidades nacionales, cuyas lenguas han sido históricamente minorizadas. La temporalidad de los encuentros (2010-2012) obedece a la conmemoración del Bicentenario de la independencia y revolución mexicanas de 2010, año significativo para México por el carácter emancipador que el gobierno otorgó a estos eventos a través de actividades dialógicas. Por ello, la selección de los encuentros se apegó a un criterio temático que se reflejara en su convocatoria:

a) El interés por ratificar los derechos fundamentales y universales de la población originaria en la legislación mexicana.

b) El interés por ratificar los derechos linguiísticos de la población originaria en el ámbito educativo mexicano.

De este modo, cuatro de las situaciones acontecieron en la Ciudad de México, y dos en el estado de Oaxaca dado su amplio poder de convocatoria hacia el sector académico y político del país, a saber:

- Coloquio 1: Conmemoración del día internacional de las lenguas maternas, celebrado del 21 al 22 de febrero de 2010 en la ciudad de Oaxaca.

- Coloquio 2: 1era Asamblea Latinoamericana de las Voces de los Pueblos, realizada los días 27, 28 y 29 de octubre de 2010 en las instalaciones del Centro Cultural Universitario Tlatelolco de la Ciudad de México. 
- Coloquio 3: El anteproyecto de ley de consulta a pueblos y comunidades indígenas y el derecho internacional, celebrado el 8 de marzo de 2011 en las instalaciones de la $\mathrm{H}$. Cámara de Diputados de la Ciudad de México.

- Coloquio 4: Primer foro de reconocimiento de los derechos de los jóvenes indígenas residentes en la Ciudad de México, realizado el 26 de marzo de 2011 en la Asamblea Legislativa del Distrito Federal.

- Coloquio 5: Consulta nacional para la reforma a la Ley General de Educación 2011, llevado a cabo el 20 de septiembre de 2011 en el Hotel Ramada de la Ciudad de México.

- Coloquio 6: Primer foro internacional «El proyecto escolar y la transformación de la escuela desde una perspectiva crítica y desarrolladora», realizado del 9 al 10 de marzo de 2012 en el Ayuntamiento de Santiago Yolomecatl, Oaxaca.

Así, por cada situación de habla (coloquio) se eligió una interacción que reflejara los requerimientos de un ECI: acciones discursivas cuya intencionalidad argumentara a favor de la diversidad cultural como principal tarea de reconocimiento y validación de la historicidad.

\section{Técnica de recolección de datos}

Se basó en la observación participante en tanto asistente recurrente a los coloquios mencionados. Al mismo tiempo, se realizó un registro en audio de los ECI seleccionados, sumando un total de 9,02 horas de grabación.

\section{Instrumentos de análisis}

Se utilizaron diarios de campo para registrar la adscripción institucional de los participantes de los coloquios, los principales temas tratados en estos y los asuntos específicos discutidos en los ECI. Para estos últimos se diseñó un formato de transcripción pragmática en donde quedaron asentadas las grabaciones en audio. Finalmente, se ocupó un cuadro de condensación para el análisis discursivo del corpus obtenido.

\section{Participantes en la investigación}

Siguiendo el criterio de selección de los ECI, el discurso registrado corresponde, por un lado, a personajes representativos del ámbito académico y político especializados en el tema de la diversidad cultural y lingüística de México y, por otro, a los asistentes interesados en discernir sobre el tema de la interculturalidad.

\section{Declaración de aspectos éticos}

Los procedimientos seguidos para el registro y análisis del corpus de los ECI cumplen con los principios y normas éticas permitidas por la Constitución de los Estados Unidos Mexicanos en lo referente al derecho para acceder a "información plural y oportuna, así como a buscar, recibir y difundir información e ideas de toda índole por cualquier medio de expresión" (artículo 6). Por tanto, el ejercicio de observación etnográfica emprendido en los lugares y periodos indicados tiene la sola intención de contribuir a la comprensión de una problemática actual y de interés internacional, como lo es el derecho a la libre determinación de los pueblos indígenas. 


\section{Resultados}

A continuación, se describe el contexto de los ECI a partir de la intencionalidad del evento de habla, es decir, de los rasgos intersubjetivos compartidos por los actores en una interacción dada en el marco de alguna de las seis situaciones de habla elegidas. De este modo, la descripción de las principales acciones comunicativas se plantea en función de la intersubjetividad compartida por los participantes del evento, la cual puede variar respecto a los contenidos que en tal suceso se discuten y para los cuales ellos fueron convocados.

Un rasgo de objetivación de los actores, como parte de la descripción del contexto, es la procedencia cultural de los mismos: variada y fluctuante. La identidad de los asistentes determina por mucho el discurso emitido en el escenario, por lo que la unidad analítica más adecuada para este fenómeno de formato público resulta ser la de evento intercultural, como concepto operativo y dependiente del discurso emitido.

\section{Clasificación de eventos comunicativos interculturales}

El siguiente cuadro ordena los componentes pragmáticos observados en los denominados Eventos Comunicativos Interculturales (ECI) y constituye un parámetro de partida para comprender, en lo posterior, las demandas surgidas en estos.

Tabla 1: Eventos interculturales (2010-2012) convocados desde el ámbito universitario

\begin{tabular}{|l|l|l|l|}
\hline \multicolumn{4}{|c|}{ Reconfiguraciones de la interculturalidad } \\
\hline \multicolumn{1}{|c|}{$\begin{array}{l}\text { Registro } \\
\text { etnográfico }\end{array}$} & \multicolumn{3}{|c|}{ Eventos comunicativos interculturales } \\
\hline Discurso & Político & $\begin{array}{l}\text { Académico } \\
\text { (nivel superior) }\end{array}$ & $\begin{array}{l}\text { De posible } \\
\text { coyuntura }\end{array}$ \\
\hline $\begin{array}{l}\text { Acciones } \\
\text { propuestas }\end{array}$ & $\begin{array}{l}\text { Planificación e } \\
\text { implementación de } \\
\text { reformas jurídicas y/o } \\
\text { acciones afirmativas }\end{array}$ & $\begin{array}{l}\text { Construcción de } \\
\text { una pedagogía } \\
\text { intercultural }\end{array}$ & $\begin{array}{l}\text { Replanteamiento del } \\
\text { concepto de "autonomía" }\end{array}$ \\
\hline $\begin{array}{l}\text { Sujetos } \\
\text { involucrados }\end{array}$ & $\begin{array}{l}\text { Funcionarios públicos } \\
\text { Asociaciones civiles (AC) } \\
\text { Dirigentes de } \\
\text { organizaciones } \\
\text { socioculturales no } \\
\text { gubernamentales (ONG) }\end{array}$ & $\begin{array}{l}\text { Investigadores } \\
\text { Profesores } \\
\text { Alumnos }\end{array}$ & $\begin{array}{l}\text { Dirigentes de } \\
\text { organizaciones } \\
\text { socioculturales no } \\
\text { gubernamentales (ONG) } \\
\text { Investigadores } \\
\text { Profesores } \\
\text { Alumnos }\end{array}$ \\
\hline $\begin{array}{l}\text { Intencionalidad } \\
\text { compartida }\end{array}$ & Derecho al desarrollo & Ética ciudadana & $\begin{array}{l}\text { Autogestión y libre } \\
\text { determinación }\end{array}$ \\
\hline
\end{tabular}

Fuente: elaboración propia.

Como puede observarse, se postulan tres tipos de encuentros interculturales: político, académico y de posible coyuntura. 
Para el caso del evento intercultural de corte político, la intencionalidad que subyace al discurso emitido por sus participantes tiende a promover el derecho al desarrollo. Para ello, la conformación de los grupos involucrados incluye a funcionarios públicos, asociaciones civiles y organizaciones no gubernamentales, que pugnan por la planificación y la implementación de reformas jurídicas para el reconocimiento de las minorías. Sin embargo, estas acciones propuestas se acercan a lo que Sartori (2001) denomina acciones afirmativas, motivo por el cual este discurso de corte político no goza de éxito entre sus interlocutores, a pesar de representar un punto de partida para un posible cambio sociocultural.

Al observar los eventos interculturales de corte académico puede apreciarse una variación respecto a la intencionalidad del discurso político en el caso anterior. En estos, las proposiciones parten de la colectividad conformada por investigadores, profesores y alumnos de nivel superior; se producen formatos discursivos públicos que apelan por una ética ciudadana plural, señal de que la perspectiva preferida por estos grupos es una construcción de políticas públicas "de abajo hacia arriba" o bottom up (Subirats et al., 2008: 189). La misma naturaleza de este discurso académico permite que los planteamientos respecto a la interculturalidad en el ámbito educativo incluyan una postura pedagógica flexible y dispuesta a reconocer las diferencias culturales, como un importante punto de partida para la práctica escolar.

Por otro lado, los eventos interculturales de posible coyuntura toman una postura menos flexible y más bien apelativa, pues se trata de formatos discursivos que representan a los grupos minorizados históricamente y, por tanto, ávidos de reconocimiento. Empero, existe un rasgo paradójico en ello que reside en la conformación de estos encuentros, pues también aquí están presentes los dirigentes de organizaciones socioculturales no gubernamentales, investigadores y profesores que se plantean como tarea primordial colocar el concepto de 'autonomía' como categoría jurídica funcional. Por lo tanto, la intencionalidad de estos eventos tiende, de principio a fin, hacia la propuesta de gobiernos autogestivos y a la libre determinación de sus grupos culturales.

La constante en estos ejercicios de reflexión colectiva es la adscripción étnica de sus participantes, y aun cuando el tema de la diversidad cultural concierne a las identidades sociales y no solo a las culturales, la presencia de estas últimas influyó en la producción discursiva de los encuentros.

\section{Configuración de los eventos comunicativos interculturales a partir de sus actores}

La presencia de diversos sectores de la sociedad es casi un requisito obligado para que las discusiones sobre la comunicación intercultural puedan llevarse a cabo: 
Tabla 2: Participantes de los eventos comunicativos interculturales

\begin{tabular}{|c|c|c|c|}
\hline \multicolumn{4}{|c|}{ Actores involucrados en la construcción de una interculturalidad convergente } \\
\hline \multirow{2}{*}{\begin{tabular}{|l} 
Bloque histórico \\
Filiación cultural
\end{tabular}} & \multicolumn{2}{|l|}{$\begin{array}{l}\text { Bloque académico } \\
\text { (profesionalizado) }\end{array}$} & \multirow{2}{*}{\begin{tabular}{|l|}
$\begin{array}{l}\text { Bloque gremial } \\
\text { (no profesionalizado) }\end{array}$ \\
$\begin{array}{l}\text { Grupos de } \\
\text { contracultura }\end{array}$ \\
\end{tabular}} \\
\hline & $\begin{array}{l}\text { Autorreconocido } \\
\text { como "indígena" }\end{array}$ & $\begin{array}{l}\text { No reconocido como } \\
\text { "indígena" }\end{array}$ & \\
\hline $\begin{array}{l}\text { Competencia } \\
\text { lingüística }\end{array}$ & \begin{tabular}{|l|} 
Bilingüe/ \\
Monolingüe \\
\end{tabular} & Monolingüe & $\begin{array}{l}\text { Bilingües/ } \\
\text { Monolingües }\end{array}$ \\
\hline Rol social & $\begin{array}{l}\text { - Investigadores } \\
\text { - Estudiantes } \\
\text { universitarios } \\
\text { - Funcionarios públicos } \\
\text { - Dirigentes de } \\
\text { organizaciones } \\
\text { socioculturales no } \\
\text { gubernamentales } \\
\text { (ONG) }\end{array}$ & $\begin{array}{l}\text { - Investigadores } \\
\text { - Estudiantes } \\
\text { universitarios } \\
\text { - Funcionarios } \\
\text { públicos } \\
\text { - Miembros de } \\
\text { organizaciones } \\
\text { socioculturales no } \\
\text { gubernamentales } \\
\text { (ONG) }\end{array}$ & $\begin{array}{l}\text { - Líderes sindicales } \\
\text { - Empleados } \\
\text { - Miembros de } \\
\text { organizaciones } \\
\text { socioculturales no } \\
\text { gubernamentales } \\
\text { (ONG) }\end{array}$ \\
\hline
\end{tabular}

Fuente: elaboración propia.

Las redes de organización y ejecución de los foros para discutir la agenda política y cultural del país parten de una iniciativa académica en la mayor parte de los casos, pues la petición de espacios no es un asunto sencillo de salvar cuando la convocatoria es amplia y se pretende diversa. Por ello, se ha dividido en dos grandes sectores la naturaleza de sus participantes, a saber: profesionalizado y no profesionalizado. La razón estriba en la combinación de factores que llevan a los sujetos interculturales a identificarse con uno u otro gremio; es decir, resulta más viable hablar de un sujeto bilingüe no profesionalizado que de un empleado que no se reconoce como indígena, pero que emprende un activismo político de contracultura. El asunto, en ambos casos, es que ese actor es relevante por el bloque histórico al que pertenece, entendido como una relación de representación en donde "se produce el intercambio de elementos individuales entre gobernantes y gobernados, entre dirigentes y dirigidos [y entonces] se realiza la vida de conjunto, la única que es fuerza social" (Portantiero, 1981: 122). También, la filiación lingüística y cultural es importante en cuanto se le dota de identidad a dicho actor, pues la lealtad le llevará a fungir en uno u otro papel dentro de la escena social y política de su entorno. Así, el reconocimiento y adscripción a un grupo diferenciado de la hegemonía cultural brinda la oportunidad de establecer grupos más cohesionados por los significados que comparten a nivel simbólico y vivencial.

\section{El derecho a la reivindicación política y cultural en México}

El rumbo histórico del reconocimiento cultural ha sido la invención o la visibilización de una entidad que pueda declararse minorizada, para así "desencadenar las reivindicaciones colectivas de los desconocidos que antes no sabían que lo eran.” (Sartori, 2001: 92)

En México, a partir de 1994, la mirada se ha puesto en el derecho a ejercer libremente la identidad cultural con todas sus implicaciones sociopolíticas. Bartra (2004) propuso, tras 
detallada crónica, cuatro categorías tendientes a una estrategia política gestada tras las movilizaciones de finales de siglo pasado y que para la década de los noventa demandaba:

1. Derecho a la autonomía y a la autodeterminación

2. Derecho a la identidad cultural

3. Derecho a la tierra y a los recursos naturales

4. Derecho a determinar libremente la condición política interna de acuerdo con las formas de organización tradicional con la vigencia del derecho consuetudinario tradicional indio (Bartra, 2004: 90)

Con esta plataforma comenzó a surgir la denominada coyuntura, en la cual temporalidad e intersubjetividad se cruzaban para concentrar en la arena política los procesos sociales, económicos, políticos y culturales del momento. Así, la conjunción de los procesos sociales es coyuntural en tanto "(...) una coyuntura es una condensación particular de espesores de la realidad y de tiempo social, en la que los procesos profundos y de larga duración están presentes más intensamente en la superficie y en el tiempo corto" (Osorio, 2001:71).

La condensación del tiempo social es mayor en periodos de crisis, sobre todo si alcanzan el rango de crisis revolucionarias con vistas a modificar las estructuras de la sociedad; se trata de momentos históricos particulares y no permanentes. En el apartado siguiente, se retoman las exigencias planteadas por las históricas organizaciones indígenas a fin de hallar alguna relación de permanencia en la agenda de los encuentros interculturales contemporáneos. Con ello se pretende dar cuenta del seguimiento que diversas iniciativas académicas y políticas han llevado a los encuentros analizados durante 2010 y 2012 en los tres tipos de eventos interculturales ya planteados.

\section{Análisis del discurso: la reflexividad sociolingüística presente en los eventos comunicativos interculturales}

Debido al seguimiento jurídico que los eventos evocan, se atenderá al formato discursivo que, desde la reflexividad sociolingüística, Muñoz (2010) denominó declaraciones temáticas, las cuales "delimitan enfática y operativamente aspectos principales del problema al cual se aplicarán normas legales" (Muñoz, 2010:1253). Estas ayudan a delimitar la naturaleza de las discusiones y el alcance de sus contenidos.

Por ello, las tablas 3, 4 y 5 condensan el seguimiento dado a la plataforma histórica formulada por Bartra (2004), a través de las declaraciones temáticas en las cuales los participantes de los ECI colocaron las categorías de lengua e identidad como aspectos prioritarios de un rediseño de políticas públicas. Para mayor comprensión del discurso emitido, se señala su profesión, cargo o función política, así como el lugar y año del encuentro.

Dichos contenidos se consideran formatos discursivos de la reflexividad sociolingüística, en tanto los propios actores cuestionan los mecanismos legales que han puesto límites al ejercicio de la agencia intercultural en México. 


\section{La agenda política respecto a la reivindicación cultural}

Los eventos de corte político en 2011 representaron una oportunidad de diálogo y reconfiguración de las disposiciones jurídicas, en aras del reconocimiento de las minorías. En este caso, nuevamente predominó el tema del indigenismo con tintes autonómicos:

Tabla 3. Declaraciones temáticas en torno a las relaciones interculturales

\begin{tabular}{|c|c|}
\hline \multirow{2}{*}{$\begin{array}{l}\text { Imperativos } \\
\text { jurídicos (Bartra, } \\
\text { 2004) }\end{array}$} & Eventos comunicativos interculturales de corte... \\
\hline & Político \\
\hline $\begin{array}{l}\text { Derecho a la } \\
\text { autonomía y a la } \\
\text { autodeterminación }\end{array}$ & $\begin{array}{l}\text { (...) algunos principios del Convenio } 169 \text { son derechos que provienen de } \\
\text { la libre determinación de los pueblos indígenas, no de la ciudadanía en } \\
\text { general, solo que el colonialismo europeo ha agravado la situación } \\
\text { haciendo caso omiso de las voces de los pueblos [por ello] una medida } \\
\text { necesaria para el Convenio } 169 \text { sería una reforma constitucional en los } \\
\text { ámbitos legislativo y administrativo de la carta magna (B. Clavero } \\
\text { Salvador, representante de ONU, H. Cámara de Diputados, comunicación } \\
\text { personal, marzo de 2011). }\end{array}$ \\
\hline $\begin{array}{l}\text { Derecho a determinar } \\
\text { libremente la } \\
\text { condición política } \\
\text { interna, de acuerdo } \\
\text { con el derecho } \\
\text { consuetudinario } \\
\text { tradicional }\end{array}$ & $\begin{array}{l}\text { (...) es necesaria una legislación que se rearticule para evitar nuevos } \\
\text { fracasos en las políticas públicas, meta que requiere de la superación de la } \\
\text { política monocultural actual y el respeto a través de la consulta (Senador } \\
\text { A. Galván Ramírez, presidente de la Comisión de Asuntos Indígenas, H. } \\
\text { Cámara de Diputados, comunicación personal, marzo de 2011). }\end{array}$ \\
\hline $\begin{array}{l}\text { Derecho a la } \\
\text { identidad cultural }\end{array}$ & $\begin{array}{l}\text { (...) en el México reconocido como multicultural desde } 1992 \text {, hay un } \\
\text { hecho sociológico importante: existen pueblos indígenas mexicanos y no } \\
\text { solo ciudadanos mexicanos (F. López Bárcenas, investigador del } \\
\text { CEDRSSA, H. Cámara de Diputados, comunicación personal, marzo de } \\
\text { 2011)). }\end{array}$ \\
\hline $\begin{array}{l}\text { Derecho a la tierra y } \\
\text { a los recursos } \\
\text { naturales }\end{array}$ & $\begin{array}{l}\text { (...) el artículo } 133 \text { constitucional -referente a la supremacía de la carta } \\
\text { magna sobre todo orden jurídico como unidad de sistema normativo- }(\ldots) \\
\text { es obsoleto y anticuado, pues no hay referencia alguna a las garantías } \\
\text { individuales de los pueblos indígenas }(\ldots) \text { debiera ser substituido, o } \\
\text { modificado, para integrar procedimientos electorales y los derechos } \\
\text { humanos en su concepción normativa (B. Clavero Salvador, representante } \\
\text { de ONU, H. Cámara de Diputados, comunicación personal, marzo de } \\
2011) \text {. }\end{array}$ \\
\hline
\end{tabular}

Fuente: elaboración propia.

Por otro lado, los eventos académicos constituyen un acercamiento a los objetivos esperados por el moderno concepto de universidad como recinto de debate, reflexión y contribución al desarrollo nacional. En las modalidades de congreso, coloquio y/o simposio, los investigadores y estudiantes universitarios discutieron el actual estado de las comunidades originarias en torno al concepto de interculturalidad como paradigma indigenista y mediador de las relaciones sociales en México. La presencia del sector indígena profesionalizado, así como de investigadores extranjeros, es alta en este tipo de encuentros, lo cual es un indicador 
de que el discurso sobre la necesaria apertura del sistema político mexicano, hacia un concepto vasto de cultura, va en incremento.

Tabla 4: Declaraciones temáticas en torno a las relaciones interculturales

\begin{tabular}{|c|c|}
\hline \multirow{2}{*}{$\begin{array}{l}\text { Imperativos } \\
\text { jurídicos (Bartra, } \\
\text { 2004) }\end{array}$} & Eventos comunicativos interculturales de corte... \\
\hline & Académico (nivel superior) \\
\hline $\begin{array}{l}\text { Derecho a la } \\
\text { autonomía y a la } \\
\text { autodeterminación }\end{array}$ & $\begin{array}{l}\text { La educación intercultural debiera ser plurilingüe en sentido amplio, abierta } \\
\text { a toda la sociedad y no solamente al sector indígena pues, seguir } \\
\text { distinguiéndole de los otros, fomenta una segregación negativa, impuesta y } \\
\text { discriminatoria (F. Sandoval, profesor triqui, Hotel Ramada de la Ciudad de } \\
\text { México, comunicación personal, septiembre de 2011). }\end{array}$ \\
\hline $\begin{array}{l}\text { Derecho a } \\
\text { determinar } \\
\text { libremente la } \\
\text { condición política } \\
\text { interna, de acuerdo } \\
\text { con el derecho } \\
\text { consuetudinario } \\
\text { tradicional }\end{array}$ & $\begin{array}{l}\text { (...) un proyecto educativo integral deviene en un gran acto político que, de } \\
\text { concretarse, recuperaría la relación entre contexto cultural, familia y escuela } \\
\text { en un programa en donde valores, pensamiento y lenguaje sean la base de } \\
\text { un trabajo en equipo (J. de Zubiria Samper, presidente de la Academia } \\
\text { Colombiana de Pedagogía y Educación, Santiago Yolomecatl, Oaxaca, } \\
\text { comunicación personal, marzo de 2012). }\end{array}$ \\
\hline $\begin{array}{l}\text { Derecho a la } \\
\text { identidad cultural }\end{array}$ & $\begin{array}{l}\text { [Es] necesario un mayor análisis de las distintas variantes [lingüísticas] dado } \\
\text { que, en aras de respetar el autorreconocimiento de los pueblos originarios, } \\
\text { se consideraron las autodenominaciones hechas por los mismos hablantes } \\
\text { hacia su código, más allá de estructuras genealógicas (V. Marcial Cerqueda, } \\
\text { director general adjunto de INALI, Oaxaca, comunicación personal, febrero } \\
\text { de 2010). }\end{array}$ \\
\hline $\begin{array}{l}\text { Derecho a la tierra } \\
\text { y a los recursos } \\
\text { naturales }\end{array}$ & contraron declaraciones temáticas. \\
\hline
\end{tabular}

Fuente: elaboración propia.

Respecto a los eventos de posible coyuntura, estos solo fueron visibles en la situación de habla conformada por el coloquio 2, pero representan una posibilidad de concientización para la población general sobre las relaciones divergentes entre Estado y comunidades indígenas.

En los ECI del coloquio 2 se plantearon opiniones y propuestas de profesionales de origen indígena sobre un desequilibrio sociopolítico en México, lo cual es indicio importante de tensión, pues, según Osorio, es en este nivel de estructura del espesor profundo donde se encuentran los grandes agrupamientos sociales, es decir, los sujetos colectivos que cimentan la organización societal: “(...) en este espesor, las historias individuales y los actores individuales no encuentran buena ubicación. Las clases sociales son quizá el más conocido y útil de los sujetos en este nivel de análisis" (Osorio, 2001: 77). 
Tabla 5: Declaraciones temáticas en torno a las relaciones interculturales

\begin{tabular}{|c|c|}
\hline \multirow{2}{*}{$\begin{array}{l}\text { Imperativos } \\
\text { jurídicos (Bartra, } \\
\text { 2004) }\end{array}$} & Eventos comunicativos interculturales de corte... \\
\hline & De posible coyuntura \\
\hline $\begin{array}{l}\text { Derecho a la } \\
\text { autonomía y a la } \\
\text { autodeterminación }\end{array}$ & $\begin{array}{l}\text { [Es necesario] tomar la iniciativa en asuntos sociales, políticos, etc., } \\
\text { recordando que los seres humanos somos arquitectos de nuestro destino y } \\
\text { esa idea debe fomentarse en generaciones posteriores. (A. Sarmiento, } \\
\text { pedagogo de origen totonaco, Centro Cultural Universitario Tlatelolco de la } \\
\text { Ciudad de México, comunicación personal, octubre de 2010) }\end{array}$ \\
\hline $\begin{array}{l}\text { Derecho a } \\
\text { determinar } \\
\text { libremente la } \\
\text { condición política } \\
\text { interna, de acuerdo } \\
\text { con el derecho } \\
\text { consuetudinario } \\
\text { tradicional } \\
\end{array}$ & $\begin{array}{l}\text { (...) es necesario promover a la "Madre Tierra" como sujeto de derecho ante } \\
\text { el creciente deterioro ambiental. (C. Pérez Bustillo, Maestría en Defensa y } \\
\text { Promoción de los Derechos Humanos de la UACM, Centro Cultural } \\
\text { Universitario Tlatelolco de la Ciudad de México, comunicación personal, } \\
\text { octubre de 2010) }\end{array}$ \\
\hline $\begin{array}{l}\text { Dere } \\
\text { iden }\end{array}$ & $\begin{array}{l}\text { (...) es imposible para cualquier ser humano hallar la identidad sin el paso } \\
\text { por la diferenciación y, justo por esta causa, la escuela es un sitio formador } \\
\text { de vacío ya que en ella no se promueve la diversidad en un sentido de } \\
\text { contraste armónico y tolerante. (R. Cardoso, Asesor Técnico Pedagógico de } \\
\text { origen mixe, Centro Cultural Universitario Tlatelolco de la Ciudad de } \\
\text { México, comunicación personal, octubre de 2010) }\end{array}$ \\
\hline $\begin{array}{l}\text { Derecho a la tierra } \\
\text { y a los recursos } \\
\text { naturales }\end{array}$ & $\begin{array}{l}\text { Bajo la denominada 'causa de utilidad pública' el Estado ha expropiado } \\
\text { numerosos recursos naturales para causas públicas que en nada benefician } \\
\text { o incluyen a los pueblos indígenas; con ello, se ha ignorado el impacto } \\
\text { ambiental de los contratos de compra-venta y arrendamiento. (F. López } \\
\text { Bárcenas, investigador del CEDRSSA, Centro Cultural Universitario } \\
\text { Tlatelolco de la Ciudad de México, comunicación personal, octubre de } \\
\text { 2010) }\end{array}$ \\
\hline
\end{tabular}

Fuente: elaboración propia.

\section{Discusión}

\section{La coyuntura como exigencia discursiva: funciones de la reflexividad sociolingüística}

El discurso emitido en los eventos de corte político cumple con la función de regular, en el marco de la legalidad, las actuales definiciones jurídicas sobre el derecho al desarrollo, reportado en la Tabla 1como la intencionalidad subyacente a estos encuentros.

Las declaraciones temáticas plantean que la armazón jurídica con la que México cuenta no cumple con los estándares del derecho internacional, una línea discontinua entre gobierno y ciudadanía que tiene su origen en los planteamientos hechos desde su carta magna. Así, se asoma de forma constante la propuesta, todavía incipiente, de modificar las leyes para dar reconocimiento a la multiculturalidad de facto, negada sistemática e históricamente en las instituciones del país. Este discurso, emitido por funcionarios públicos desde la vía protocolaria, no constituye todavía un discurso de posible coyuntura ya que, entre otros factores, el enunciador es el administrador y ejecutor de la normatividad vigente. 
Se trata de un discurso en donde se pretenden orientaciones de acción no ambiguas y con objetivos legalmente establecidos, unívocos, claros; directivas que los actores afectados aprueban tácitamente. Es, pues, una función discursiva de planeación política "de arriba hacia abajo" o top down, en donde "se parte de la hipótesis de que es posible separar netamente elaboración y puesta en práctica de una política, y que los «implementadores» son de hecho los «(agentes» de los que han decidido" (Subirats, 1994: 111).

Ocurre algo similar respecto a los eventos de corte académico. En ellos, la constante es discutir el devenir de la educación intercultural, contrastando entre sus fundamentos y aplicación. Al respecto, se disparan dos alternativas de razonamiento:

1) Cuando el enunciador no se autorreconoce como indígena y bilingüe, ocurre que la lengua indígena se percibe como rasgo de enriquecimiento cultural y, por tanto, merecedora de un estatus de acreditación oficial dentro del sistema educativo mexicano en todos sus niveles. No se entiende claramente si con esto se apela a la enseñanza de una lengua nacional en los centros educativos a modo de opción curricular o se postula una lengua nacional como vehículo de enseñanza.

De lo anterior, se sigue que el concepto de interculturalidad se percibe, en general, como una convivencia con las comunidades autóctonas del país y no necesariamente con las múltiples filiaciones culturales que ocurren factualmente entre los sujetos sociales. Pocos son los académicos que señalan el error categorial de aplicar un solo proyecto de nación para una que es plural en su composición y, derivado de ello, la equivocación de concebir un proyecto educativo discordante con los intereses de su población:

(...) un solo proyecto nacional para una nación plural no resulta coherente. Es necesario considerar el bilingüismo como derecho para todos los mexicanos, pues se ha impedido el diálogo abierto entre culturas: una suerte de fundamentalismo que ignora lo 'indígena' (E. Díaz Couder, Hotel Ramada de la Ciudad de México, docente de la Universidad Pedagógica Nacional, comunicación personal, septiembre de 2011).

2) Cuando el enunciador se reconoce como indígena y bilingüe, las reflexiones sobre la educación intercultural en México rescatan la apertura de esta hacia sectores no necesariamente indígenas. Así, se propone una pluriculturalidad que no segregue a los originarios:

(...) la situación del bilingüismo en México debe alcanzar un nivel de proficiencia tal que sea posible observar un fenómeno de bilingüismo equilibrado, con vistas a una sociedad incluyente (G. Caballero Morales, lingüista mixteco del Instituto Estatal de Educación Pública de Oaxaca (IEEPO), Oaxaca, comunicación personal, febrero de 2010).

El problema de aceptar la diversidad como enriquecimiento se ha enfocado, desde el discurso académico, en el tema linguístico. El discurso de este sector profesionalizado enfatiza las culturas y las lenguas originarias como elementos de reivindicación; así, los investigadores de origen indígena argumentan a favor del registro y el análisis de las distintas variedades de 
lengua como solución al conflicto de la normalización y posterior estandarización: temas con una importante repercusión política al considerar que la filiación linguiística deviene en fortalecimiento identitario.

Por un lado, se demanda el análisis lingüístico o política del lenguaje interna, la cual "analiza la intervención sobre las normas gramaticales, la codificación, estandarización, la elaboración de alfabetos y vocabularios" (Hamel, 1993: 8); y por otro, se aprecia necesaria la paulatina aplicación de estos recursos pedagógicos en una suerte de apertura curricular organizada en dos momentos: primero, hacia los sectores inmediatos e involucrados con la reivindicación de su patrimonio lingüístico (la comunidad lingüística misma); luego, con los sectores inmediatos que deseen, o deban, conocer su patrimonio cultural en una suerte de política del lenguaje externa, es decir, aquella que "se refiere al papel de cada lengua (...) sus usos y funciones en un contexto multilingüe" (Hamel, 1993: 8). La relevancia de este tipo de discurso académico radica, desde el punto de vista etnográfico, en agrupar a diversos colectivos para ahondar en temas de importancia nacional desde una plataforma educativa e informativa crucial para elaborar otra perspectiva de análisis y aplicación de la llamada educación intercultural en México, pues, al repensar sus fundamentos, contextos, actores e impactos, se está planeando - aunque todavía desde una perspectiva top down- otro diseño de política del lenguaje intercultural para el país.

La misma sensación de aparente ruptura con las instancias gubernamentales y su consecuente reestructuración fue percibida en los eventos denominados de posible coyuntura. En estos, todos los puntos de la agenda inspirada en el análisis de Bartra (2004) fueron cubiertas, predominando abiertamente la desacreditación del gobierno y la inminente participación de la ciudadanía. No fue en estos casos el concepto de interculturalidad la relevancia temática; lo fue el efecto que causa una convivencia conflictiva y desigual entre ciudadanos de un mismo Estado: la necesidad de autonomía, entendida como el derecho a la autogestión y libre determinación.

Durante el periodo registrado no hubo formatos discursivos públicos tendientes a la reconfiguración legal, o propuestas de participación ciudadana a corto o mediano plazo en dichos eventos. El tipo de racionalidad emitida por sus enunciadores no alcanzó lo que Muñoz (2010) denominó proposiciones argumentativas, en tanto no constituyen "estructuras de interpretación de experiencias, problemas y necesidades que permiten a los sujetos asumir alguna posición frente al fenómeno sociolingüístico por regular” (p. 1254).

Nociones como "el ser mestizo" frente al "ser indígena" fueron recurrentes, abonando en poco, o nada, al tema de la interculturalidad convergente. Los colectivos participantes en estos foros obedecían a su identificación con el indigenismo, mientras que los individuos pertenecientes a comunidades originarias, sin importar su rol social, fueron sujetos de demandas justificadas en razones, pero sin seguimiento propositivo para su posible solución en temas tales como discriminación racial, lingüística, educativa y laboral.

La función discursiva de estos eventos, contrario a lo postulado por las declaraciones temáticas, tampoco fue coyuntural en tanto no ocurrió un consenso respecto a los significados compartidos por los asistentes. El fenómeno de la interculturalidad divergente, por tanto, no fue resuelto porque no se cumplió la función de postular nuevas definiciones sobre la 
autonomía, libre determinación y autogestión, conceptos presentes en la Tabla 1 como la intencionalidad subyacente a estos encuentros y la cual, aunque siempre presente, no halló materialización en actas, acuerdos publicados o la sugerencia de próximos encuentros. Con lo anterior, puede definirse la función de los diferentes eventos comunicativos interculturales como sigue:

Tabla 6: Funciones discursivas de los ECI

\begin{tabular}{|l|l|l|l|}
\hline \multicolumn{3}{|l|}{ Eventos comunicativos interculturales } \\
\hline Usos del discurso & Político & $\begin{array}{l}\text { Académico } \\
\text { (nivel superior) }\end{array}$ & $\begin{array}{l}\text { De posible } \\
\text { coyuntura }\end{array}$ \\
\hline Función & $\begin{array}{l}\text { Enfatizar en las } \\
\text { culturas y lenguas } \\
\text { originarias como } \\
\text { elementos de } \\
\text { reivindicación } \\
\text { identitaria }\end{array}$ & $\begin{array}{l}\text { Postular nuevas } \\
\text { definiciones y } \\
\text { propuestas } \\
\text { consensuadas sobre } \\
\text { una problemática } \\
\text { nacional }\end{array}$ \\
\hline
\end{tabular}

Fuente: elaboración propia.

En México no ha habido, hasta hoy, un proceso organizativo similar al registrado por Bartra; sin embargo, cierta voluntad de ruptura aún hoy día es visible en el marco de un discurso público académico, pues a diferencia de lo ocurrido hace 20 años, hoy los escenarios del diálogo no son las calles en primera instancia, sino los auditorios, salas y foros de iniciativa formal o informal. Todos ellos con el común rasgo de orbitar en torno a un recinto universitario de donde sus organizadores son egresados y promotores del cambio político y cultural gestado en décadas anteriores, como se verá a continuación.

\section{Discursos reflexivos en torno a la interculturalidad convergente}

Los discursos sobre el derecho al desarrollo, la necesidad de una ética ciudadana, así como de la autogestión y libre determinación en los eventos registrados, en pocas ocasiones fueron propositivos o reflexivos. La explicación más lógica para esto se desprende del formato de la mayoría de los encuentros: conferencias, ponencias, breves rondas de preguntas y respuestas, pero rara vez existió la disposición y logística para ejecutar un ejercicio de debate.

La exigencia de la coyuntura, según Osorio (2001), se manifiesta en la condensación del tiempo social, lo que podríamos entender como un cruce de intersubjetividades, un preámbulo del acuerdo y la toma de decisiones. Este fenómeno se empieza a manifestar en lo que Muñoz (2010) ha llamado proposiciones argumentativas, y un caso ejemplar lo constituyen diversos testimonios registrados durante el debate convocado por el ler Foro de reconocimiento de jóvenes indígenas residentes en la Ciudad de México de 2011 (coloquio 4), único intercambio comunicativo que hizo especial énfasis en la política educativa superior del país y cuyos testimonios provinieron predominantemente de jóvenes bilingües universitarios. La relevancia de este ECI radica en que recupera todos los aspectos de la agenda política pendiente sobre el tratamiento a la diversidad cultural desde hace años demandada. 
Por ello, en los siguientes fragmentos se vislumbran propuestas de reordenamiento político a través de proposiciones argumentativas que apuntan hacia:

1) El reconocimiento de las autonomías. La alternativa del autorreconocimiento para transitar, como sujeto histórico, por la vía de los derechos fundamentales y universales.

Entonces, me pregunto ¿cómo transitar? y digo transitar del indigenismo a una política con enfoque de derechos (Z. Hernández, Asamblea Legislativa del D.F, comunicación personal, 26 de marzo de 2011).

2) La apertura del sistema político. Se retoma la noción de ciudadanía, recordando que los individuos pertenecientes a una comunidad, o pueblo indígena, no solo pueden reclamar derechos culturales, sino también los derechos económicos, sociales y políticos a los que cualquier ciudadano mexicano tiene acceso por mandato constitucional.

Acaso me pregunto ¿solo tenemos derechos lingüísticos? ¿Acaso solo tenemos derechos culturales? ¿Acaso solo podemos expresarnos culturalmente y no políticamente y no socialmente y no culturalmente y no económicamente? (Z. Hernández, Asamblea Legislativa del D.F, comunicación personal, 26 de marzo de 2011).

3) Una reforma educativa. Se asume que no es un problema específico de los estudiantes originarios, sino un asunto de índole nacional que requiere un rediseño y extensión del currículo hacia una perspectiva intercultural de cobertura nacional, como solución al modelo dicotómico educativo:

Acuérdense ustedes que en nuestros pueblos no hablamos de individualidad, hablamos de colectividades, hablamos de 'nosotros' siempre en forma colectiva. Entonces, habría que tener mucho cuidado en el enfoque, eso es algo que yo quiero recalcar mucho porque la percepción, la cosmovisión, tiene que salir de nuestras comunidades (R. Pérez López, mixteca de Oaxaca, Asamblea Legislativa del D.F, comunicación personal, 26 de marzo de 2011).

4) Una reconfiguración sobre lo nacional. Un cambio en las representaciones sociales sobre las identidades indígenas, pues se asoma la riqueza del diálogo intercultural a partir de las múltiples cosmovisiones que subyacen a las lenguas originarias.

Yo estoy a favor, estoy contento de que haya diversidad cultural en México, diversidad lingüística, diversidad de pensamiento, pero creo que también eso no implica que haya desunión, o sea, diversidad no significa necesariamente desunión, tenemos que mirar hacia el mismo objetivo. Perseguimos lo mismo, perseguimos dignidad, perseguimos trabajar dignamente, perseguimos ser respetados como diría nuevamente el maestro, lo cito: "prevalecer y florecer", ¿no? En ese sentido creo que el hecho de que seamos diversos es enriquecedor porque nos permite llegar a acuerdos, llegar a decisiones útiles, dos cabezas piensan más que una, veintitrés lenguas seguramente mucho más (S. Rivero Co, maya yucateco, Asamblea Legislativa del D.F, comunicación personal, 26 de marzo de 2011). 
5) Un cambio sociocultural. La información sobre los acuerdos internacionales y las leyes derivadas de la constitución mexicana son la mejor arma en defensa del reconocimiento y la participación equitativa de las comunidades indígenas en la vida política nacional.

Lo que yo decía hace un momento es cuestión de acción, es cuestión de identificar qué puedo hacer yo, cómo lo puedo hacer, a quienes tengo que recurrir, entonces. A partir de la Ley General de Derechos Lingüísticos y del propio artículo dos constitucional, nos faculta o faculta a las autoridades para diseñar estrategias y diseñar políticas públicas que nos atiendan a los pueblos originarios, concretamente aquellos que nos sentimos identificados ¿no? Y los jóvenes, por supuesto, creo que son la materia viva, que ustedes pueden modificar muchas cosas que no están bien (Anónimo, otomí del Estado de México, Asamblea Legislativa del D.F, comunicación personal, 26 de marzo de 2011).

\section{Conclusión}

Desde un punto de vista social, el uso de la lengua sigue una lógica de regulación que no siempre es percibida por sus usuarios, y así también ocurre con los formatos y las funciones que este produce. Ello ha sido constatado por la sociolingüística de fin de siglo, la cual contribuyó a retomar la subjetividad como una de las variables más importantes para explicar el cambio y el desplazamiento lingüístico (cf. Fishbein, 1966; Lambert, 1972; Fishman, 1974). Paulatinamente, los trabajos sobre el conflicto intercultural que subyace a las sociedades multilingües como México han incorporado la noción de resistencia a su campo de estudio, abriendo el panorama hacia lo que actualmente se conoce como Sociolingüística de la globalización (Blommaert, 2010) y hacia una interdisciplinaria y creciente Política del lenguaje en la cual "podemos ver el penetrante y contestatario rol del lenguaje en la arena política, económica, laboral, educativa, deportiva, tecnológica, mediática, y en la construcción de identidades nacionales individuales y grupales" (McCarty, 2011: 2).

A través de la etnografía del habla también es posible concebir el lenguaje como un conjunto de prácticas de simbolización que configuran el accionar político de una comunidad. En Reinventando la antropología. Hymes (1974) argumentaba apasionadamente por una etnografía "para la gente para quien 'la manera en que las cosas son' no es razón suficiente para que las cosas sean" (p. 53), una etnografía que ayuda a construir "un mundo cultural que es una comunidad moral" (p. 53) pues, si este compromiso no se cumpliera, "nuestro trabajo se irá a la deriva al servicio de la dominación" (p. 54).

Considerando que uno de los objetivos de la etnografía del habla es mantener la complejidad del lenguaje como praxis, para no reducirla a una serie de principios abstractos e independientes del contexto social, la clasificación de los ECI aquí mostrados resultó útil para caracterizar el despliegue de contenidos que conformaron, en un periodo temporal determinado, la agenda de órganos de gobierno, universidades y Organizaciones No Gubernamentales a favor de la diversidad cultural de México.

Al respecto, la reflexividad sociolingüística muestra en las declaraciones temáticas las estrategias seguidas por sus enunciadores por mantener en la agenda nacional las 
problemáticas que llevaron años atrás a una etapa que, por poco, marcó un auténtico cambio sociocultural en el país. Las proposiciones argumentativas, sin embargo, no lograron establecer un acuerdo unitario respecto a una nueva agenda o, al menos, el seguimiento de la anterior. Es por esta ausencia de análisis y sistematización de las declaraciones temáticas que no es posible hablar de un discurso coyuntural y propositivo que articule, al menos desde esta perspectiva etnográfica, una interculturalidad convergente. Sin embargo, sí es posible hablar de tensión en un espesor profundo (Osorio, 2001) de la sociedad en donde se entraña un discurso concerniente a la reivindicación cultural como representación colectiva, afectiva y explicativa sobre el devenir lingüístico de los pueblos originarios, así como de las posibles relaciones interculturales al interior de la nación mexicana.

Para entender la dinámica de los ECI presentados es necesario considerar que existen al menos dos tipos de coyuntura: una en la que "los cambios en las correlaciones de fuerza permiten hacer modificaciones sustanciales en los grandes bloques sociales gestados por la crisis social, pero sin alterar radicalmente la relación entre clases dominantes-clases dominadas"; y otra de tipo revolucionario, en donde "los cambios en las correlaciones de fuerza permiten modificar radicalmente aquella relación” (Osorio, 2001: 75).

Por tanto, lo ocurrido en México a partir de la década de los ochenta, comportó el primer tipo de coyuntura mencionado debido a que, aún con las fuertes movilizaciones y agrupaciones políticas, no se modificó la relación entre las clases integrantes de la población mexicana y sus gobiernos. Por ello, el reto de las organizaciones culturales actuales -indígenas o noes definir su estrategia como movimiento social, sumado a otros sectores populares: una postura política que ha encontrado en el discurso sobre la interculturalidad un espacio de permanente negociación y contención de las autonomías.

\section{Agradecimientos}

Esta investigación contó con el apoyo moral y económico del proyecto Dominio lingüístico y académico de estudiantes bilingües indígenas en algunas universidades de México: habilidades comunicativas y académicas, reflexividad sociolingüística y políticas interculturales del lenguaje, patrocinado por el Consejo Nacional de Ciencia y Tecnología (CONACyT), con número de registro 99274. A todos los integrantes del equipo de trabajo: gracias.

\section{Referencias}

Bartra, A. (2004). Las guerras del ogro. Chiapas, 16, 63-106.

Bennett, M. (1993). Towards ethno relativism: A developmental model of intercultural sensitivity. En Paige M. (Ed.), Education for the intercultural experience [pp. 21-71]). Yarmpunt: Intercultural Press.

Blommaert, J. (2010). The sociolinguistics of globalization. Cambridge: Cambridge University Press.

Constitución Política de los Estados Unidos Mexicanos [Const.]. (5 de febrero de 1917). [Reformada el 6 de junio de 2019]. México: Diario Oficial de la Federación. Recuperado de http://www.diputados.gob.mx/LeyesBiblio/ref/cpeum.htm

Duranti, A. (2000). Antropología lingüística. Madrid: Cambridge, University Press. 
Hamel, R. E. (1993). Políticas y planificación del lenguaje: una introducción. Iztapalapa, 29, 5-39.

Hymes, D. (1964b). Introduction: toward ethnographies of communication. En Gumperz J. J. y Hymes D. (Eds.), The ethnography of communication "Special issue" [pp. 1-34]. Washington, DC: American Anthropologist.

. (1972a). Models of the interaction of language and social life. En Gumperz J. J. y Hymes D. (Eds.), Directions in sociolinguistics: the ethnography of communication [pp. 35-71]. New York: Holt, Rinehart and Winston.

. (1974), Reinventing anthropology. New York: Random House.

Instituto Nacional de los Pueblos Indígenas (INPI) (2019). El INPI propone el reconocimiento de la educación indígena, intercultural y plurilingüe en el Sistema Educativo Nacional. México: INPI. Disponible en: https://www.gob.mx/inpi/prensa/elinpi-propone-el-reconocimiento-de-la-educacion-indigena-intercultural-y-plurilingueen-el-sistema-educativo-nacional-191276?idiom $=\mathrm{es}$

McCarty, T. L. (Ed.). (2011). Ethnography and language policy. New York: Routledge.

Muñoz Cruz, H. (2008) Reflexividad sociolingüística de hablantes de lenguas indígenas: concepciones y cambio sociocultural (Tesis doctoral), Centro de estudios lingüísticos y literarios del Colegio de México, Ciudad de México, México.

Muñoz Cruz, H. (2010). Significado y filiación de las políticas de lenguas indoamericanas. ¿Diferente interpretación y regulación de las hegemonías sociolingüísticas? En Barriga Villanueva R. y Butragueño P. M. (Dirs), Historia sociolingüística de México [pp. 12411270]. México: El Colegio de México.

Osorio, J. (2001). Fundamentos del análisis social. La realidad social y su conocimiento. México: UAM-X, FCE.

Portantiero, J. C. (1981). Los usos de Gramsci. México: Folios Ediciones.

Sartorello, S. (2019). La agenda pendiente de la educación intercultural bilingüe en México. México: Instituto Nacional para la Evaluación de la Educación (INEE). Disponible en: https://www.inee.edu.mx/la-agenda-pendiente-de-la-educacion-intercultural-bilingueen-mexico/

Sartori, G. (2001). La sociedad multiétnica. Pluralismo, multiculturalismo y extranjeros. México: Taurus.

SEP-CGEIB (2014). Programa especial de educación intercultural 2014 - 2018. México: Diario Oficial de la Federación (DOF). Disponible en: http://dof.gob.mx/nota_detalle.php?codigo=5342484\&fecha=28/04/2014

Subirats, J. (1994). Análisis de políticas públicas y eficacia de la administración. Madrid: MAP.

Subirats, J., Knoepfel, P., Larrue, C. y Varone, F. (2008). Análisis y gestión de políticas públicas. Barcelona: Ariel. 